\title{
Unsur Tambahan dalam Frase Adjektiva
}

\author{
Ary Setyadi \\ Fakultas Ilmu Budaya, Universitas Diponegoro \\ arysetyadi58@gmail.com
}

\begin{abstract}
The adjective phrase consists of two functional elements, namely the core function which is filled by the adjective word (nature / state); and elements of function attributes, which are filled by additional elements (words added / adverbs); so understanding the adjective phrases can be explained: a combination of two or more words that made up the word adjective as the core element / center, and word / additional elements (words added / adverb) as attributes. Based on the data, it turns out the presence of additional elements in the adjective phrase has not received special attention by some Indonesian experts; so interestingly researched. Implementation of the strategic research base three stages, namely: I. provision / collection of data, II. Classification and data analysis, and III. Preparation / report writing. Phase I, the data obtained at the data source, both oral and written sources by referring method and recording technique. Phase II based on the behavior of additional elements on its ability to join the word adjective (nature / circumstances) as attributes and are optional. The data analysis is based on the application of linguistic theory in the field of syntax with the application of the 'direct elements' method with techniques: substitution, deletion, expansion, permutation, and phrases. In accordance with the objectives to be achieved, which includes: 1. kinds of additional elements, which finally can be found many additional elements. 2. distribution / provision of an additional element layout, which ultimately has three distribution: a. located in front, b. located at the back; and c. can be located in front or behind. 3. The power capability of additional elements, which can eventually be found in combination of two or more additional elements. Phase III is ended by being able to present a research / study report as the objective to be achieved.
\end{abstract}

Kunsi words: Phrase, Adjective Phrases, words Add / adverb, Additional Elements

\section{Intisari}

Frase adjektiva terdiri atas dua unsur fungsi, yaitu fungsi inti/pusat yang diisi oleh kata adjektiva (sifat/keadaan); dan unsur fungsi atribut, yang diisi oleh unsur tambahan (kata tambah/adverbia); sehingga pengertian frase adjektiva dapat dijelaskan: gabungan dua kata atau lebih yang terdiri atas kata adjektiva sebagai unsur inti/pusat, dan kata/unsur tambahan (kata tambah/adverbia) sebagai atribut. Berdasarkan data, ternyata keberadaan unsur tambahan dalam frase adjektiva belum mendapat perhatian secara khusus oleh beberapa pakar bahasa Indonesia; sehingga menarik diteliti. Pelaksanaan penelitian mendasarkan tiga tahapan strategis, yaitu: I. penyediaan/pengumpulan data, II. klasifikasi dan analisis data, dan III. penyusunan/penulisan laporan. Tahap I, data diperoleh pada sumber data, baik sumber lisan maupun sumber tulis dengan metode simak dan teknik 
pencatatan. Tahap II mendasarkan pada perilaku unsur tambahan atas kemampuannya bergabung dengan kata adjektiva (sifat/keadaan) sebagai atribut dan bersifat opsional. Adapun analisis data mendasarkan pada penerapan teori linguistik bidang sintaksis dengan penerapan metode 'pembagian unsur langsung` dengan teknik: substitusi, delesi, ekspansi, permutasi, dan para frase. Sesuai dengan tujuan yang hendak dicapai, yang mencakup: 1. macam wujud unsur tambahan, yang akhirnya dapat ditemukan sekian banyak unsur tambahan. 2 . distribusi/ketentuan letak unsur tambahan, yang akhirnya dapat ditemukan tiga distribusi: a. terletak di depan, b. terletak di belakang; dan c. dapat terletak di depan atau di belakang. 3. Kemampuan daya gabung antarunsur tambahan, yang akhirnya dapat ditemukan gabungan dua atau lebih antarunsur tambahan. Tahap III berakhirnya dengan dapat disajikan sebuah laporan penelitian/kajian sebagaimana tujuan yang hendak dicapai.

Kata Kunsi: Frase, Frase Adjektiva, Kata Tambah/Adverbia, Unsur Tambahan

\section{Pendahuluan}

Persoalan frase merupakan ranah sintaksis, sebab kajian sintaksis mencakup: kata, frase, klausa, kalimat, wacana (Kentjono (Ed.), 1982: 61; Ramlan, 1983: 20). sehingga bahasan frase selalu ada dalam buku yang membicarakan sintaksis. Salah satu jenis frase adalah frase adjektiva, yaitu sebuah konstruksi yang berpola struktur unsur inti dan unsur atribut. Unsur inti diisi oleh kata yang berketegori adjektiva (sifat/keadaan), sedang unsur atribut diisi oleh kata yang berkategori kata tambah/adverbia.

Pengertian adverbia mencakup: 1. sebagai fungsi unsur(-unsur) kalimat, dan 2. sebagai kategori/kelas kata. Pengertian adverbia adalah, "Kata yang dipakai untuk memerikan verba, ajektiva, atau adverbia lain; mis. Sangat, lebih, tidak, dsb." (Kridalaksana, 2001: 2). Disebut kata tambah sebab berfungsi sebagai atribut dalam frase endosentrik atributif, dan unsur inti diisi oleh kata verbal. Sedangkan verbal mencakup kata kerja dan kata sifat (Ramlan, 1983:50; 53).

Kata adverbia/kata tambah yang mengisi unsur atribut itulah yang menjadi objek kajian (dalam artikel ini), dan disebut dengan istilah unsur tambahan. Sebab pola struktur internal frase adjektiva terdiri atas gabungan antara kata yang berkategori kata adjektiva dengan kata yang berkategori kata tambah (yang berfungsi sebagai unsur tambahan).

Keberadaan unsur tambahan frase adjektiva dalam beberapa buku sintaksis relatif belum/tidak dibahas secara khusus, sehingga menarik untuk dikaji. Adapun 
tujuan pengkajian mencakup:1. macam wujud katanya, 2. distribusi/ketentuan letak, dan 3. kemampuan daya gabung antarunsur tambahan.

\section{Metode Penelitian}

Penerapan metode penelitian mendasarkan tiga tahap strategis sebagaimana penelitian linguistik pada umumnya, yaitu: 1. tahap penyajian/pengumpulan data, 2. tahap klasifikasi dan analisis data, dan 3. tahap penyusunan penulisan laporan (Sudaryanto, 1982: 7-11).

Tahap penyajian/pengumpulan data bertolak pada, baik data primer maupun data sekunder, dengan bersumber data, baik dari ragam lisan maupun tulis. Sumber data lisan menghasilkan data primer, dan sumber tulis menghasilkan data sekunder; dan diberlakukan secara berimbang.

Data primer menemukan kemampuan daya gabung antarunsur tambahan, sedang data sekunder berkait dengan macam wujud satuan dan bagaimana distribusi/ketentuan letaknya. Adapun metode yang diterapkan dalam pengumpulan data adalah metode simak dengan teknik pencatatan (dalam kartu data).

Tahap klasifikasi dan analisis data. Klasifikasian data mendasarkan pada: 1 . apakah kata yang ada berstatus sebagai unsur tambahan, dan berfungsi sebagai atribut; 2. berkemungkinan berpindah tempat, dan 3. berkemampuan berdaya gabung. Setelah data diklasifikasikan lalu dilakukan analisis data.

Analisis data mendasarkan pada penerapan teori linguistik bidang sintaksis, yaitu dengan penerapan metode 'pembagian unsur langsung'. Sebab apa yang disebut frase adjektiva, dapat ditentukan unsur pembentuknya. Adapun teknik analisis data mencakup: substitusi, delesi, ekspansi, permutasi, dan parafrase.

Tahap terakhir adalah tahap penyusunan/penulisan laporan. Pada tahap ini berakhir pada sajian hasil pengkajian, sehingga didapatkan sebuah laporan berbentuk artikel ini.

Sajian di bawah ini merupakan sajian tinjauan pustaka, dengan mendasarkan pada beberapa sumber bacaan/referensi yang tersedia.

Verhaar dalam buku Pengantar Linguistik (1977: 78-80) menyinggung kata sifat dalam bahasan fungsi bawahan. Contoh: meja berat. Terdiri dari berat 
sebagai atribut, dan meja sebagai "yang diatributi". Adapun bahasan frase adjektiva dan unsur tambahan tidak disinggung sama sekali.

Buku Ilmu Bahasa Indonesia: Sintaksis (Ramlan, 1981: 121, 128) telah menyinggung frase, dan frase verbal. Yaitu, "Satuan gramatik yang terdiri dari dua kata atau lebih yang tidak melampui batas fungsi”, dan berciri: 1. frase merupakan satua gramatik yang terdiri dari dua kata atau lebih, dan 2. satuan gramatik frase hanya menduduki satu fungsi saja dalam tataran kalimat.

Pembicaraan frase adjektiva dalam frase verbal. Contoh: sering sakit. Kata sering menduduki fungsi atribut, sedang kata sakit menduduki fungsi inti/pusat. Contoh: mungkin, barangkali,amat, sangat, kurang, sekali,dan masih banyak lagi.

Buku lain Tata Bahasa Indonesia: Penggolongan Kata (Ramlan, 1985: 49; 53), tidak ada bahasan frase adjektiva, sebab frase tersebut menyatu dalam frase verbal. Ciri frase verbal berpola: dengan sangat ... (kata + dengan sangat...). Lebih lanjut disinggung kata tambah, dan dijelaskan: bahwa kata tambah berada dalam konstruksi frase endosentrik atributif. Keberadaan kata verbal sebagai unsur inti/pusat, sedang kebarasaan kata tambah sebagai unsur atribut. Adapun contoh kata yang termasuk golongan kata tambah, misalnya: tentu, pasti, tidak, akan, belum.

Kridalaksana dalam buku Kelas Kata dalam Bahasa Indonesia (2007: 59: 81) membicarakan kelas kata ajektiva (bukan adjektiva) yang secara tegas dikatakan, "Kategori yang ditandai oleh kemungkinannya untuk: 1. bergabung dengn partikel tidak, 2. mendampingi nomina, atau 3. didampingi partikel seperti: lebih, sangat, agak, 4. mempunyai ciri morfologis...".

Frase adjektiva dibedakan menjadi tiga, yaitu a. frase ajektival modifikatif, contoh: alangkah merdu; b. frase ajektival koordinatif, contoh: makmur dan sejahtera; c. frase ajektival apositif, contoh: gagah - katakan perkasa. Pada konstruksi frase adjektival modifikatif sebagaimana contoh alangkah merdu merupakan bukti adanya kata adjektiva, yaitu kata merdu, sedang kata alangkah disebut dengan adverbia; sebab keberadaannya dapat mendampingi adjektiva, numeria, atau proposisi dalam konstruksi sintaksis.

Buku Tata Bahasa Baku Bahasa Indonesia (Moeliono (Ed.), 1988: 209; 220) membicarakan, baik kata maupun frase adjektiva/sifat/keadaan. Kata adjektiva dikatakan berciri: dapat diberi keterangan pembanding seperti: lebih, kurang, 
saling; dan lebih besar, kurang baik, paling mahal; juga dapat diberi keterangan penguat, seperti: sangat, amat, benar, sekali, dan terlalu. Sedangkan apa yang disebut dengan frase adjektiva berciri dapat diberi keterangan penguat seperti: sangat, amat, terlalu.

Surono dalam buku Analisis Frasa-Kalimat Bahasa Indonesia (Surono, 2014: 37) telah menyinggung frase adjektiva, dengan istilah frasa adjektival, dan dikatakan, "Gabungan sintaksis dua kata atau lebih yang berunsur inti adjektiva, dan unsur tambahan atau atributnya berupa adverbia seperti: amat, sangat, terlalu, nian, sekali.". Persoalan unsur tamabahan dalam frase adjektiva belum disinggung sama sekali.

Bertolak dari beberapa sajian sajian pustaka di atas, tampak jelas bahwa persoalan unsur tambahan dalam frase adjektiva belum dibahas secara khusus dan mendalam, sehingga perlu dikaji tersendiri sebagaimana dalam artikel ini.

\section{Pembahasan}

Sajian pembahasan mencakup: 1. macam wujud unsur tambahan, 2. distribusi/ketentutuan letak unsur tambahan, dan 3. kemampuan daya gabung antarunsur tambahan. Masing-masing permasalahan dibahas tersendiri.

\section{Macam Wujud Unsur Tambahan}

Sajian bahasan 'macam wujud unsur tambahan` bermula dari penjelasan unsur tambahan, sehingga bahasan berkait dengan upaya pembuktian penentuan kepastian apa itu unsur tambahan.

Ramlan dalam buku Tata Bahasa Indonesia Penggolongan Kata (1985: 53) membahas kata tambah, dan dikatakan berada pada farse endosentrik artibutif. Yaitu menduduki fungsi atribut, sedang fungsi unsur inti diisi oleh kata verbal, yaitu khususnya diisi oleh kata sifat (adjektiva). Sebab kata verbal mencakup kata kerja dan kata sifat. Sedangkan frase adalah, "Satuan gramatik yang terdiri dari dua kata atau lebih yang tidak melampui batas fungsi.", dengan sifat:1. frase merupakan satuan gramatik yang terdiri dari dua kata atau lebih, dan 2. frase 
hanya berada pada satu fungsi tertentu (S, P, O, PEL, KET). Contoh frase yang berunsur atribut + kata sifat: sangat bangga. Kata sangat sebagai unsur atribut, sekaligus sebagai kata tambah; sedang bangga sebagai unsur inti, sekaligus sebagai kata sifat.

Sumber lain dalam buku Kelas Kata dalam Bahasa Indonesia (Kridalaksana, 2007: 126), unsur tambah dalam frase modifikatif. Contoh: cantik nian. Kata cantik sebagai kata ajektiva, sedang nian sebagai (kata) adverbia. Frase cantik nian dapat dianalisis atas fungsinya, yaitu kata cantik menduduki inti, sedang kata nian menduduki fungsi atribut (yang berkategori adverbia).

Buku berjudul Analisis Frasa-Kalimat Bahasa Indonesia (Surono, 2014: 37), batasan frase adjektiva (dipakai istilah adjektival) dijelaskan, "Gabungan dua kata atau lebih yang berunsur inti adjektiva, dan unsur tambahan atau atributnya berupa adverbia seperti: amat, sangat, terlalu nia, sekali,...”

Bertolak dari ketiga sumber di atas, akhirnya dapat disimpulkan, bahwa apa yang disebut unsur tambahan dalam frase adjektiva berciri: 1. semua kata yang dapat menduduki fungsi unsur atribut, 2. sebagai atribut berperan sebagai `keterangan`atas unsur inti, dan 3. keberadaannya bersifat opsional. Contoh:

(1) Adik Bandi sangat gemuk.

(2) Sungai Bengawan Solo lebar sekali.

(3) Orang tua Halimah amat kaya nian.

(4) Anjing putih itu memang lebih galak.

Keempat data di atas tampak jelas bahwa kehadiran kata: sangat, sekali, amat...nian, dan memang lebih merupakan unsur tambahan dalam frase adjektiva: sangat gemuk, lebar sekali, amat kaya nian, dan memang lebih galak menduduki fungsi atribut; dan sekaligus berperan sebagai 'keterangan` atas unsur inti yang diisi oleh kata: gemuk, lebar, kaya, dan galak. Sedangkan sifat opsional dapat dibukti oleh sajian data (1a, 2a, 3a, 4a).

(1a) Adik Bandi (...) gemuk.

(2a) Sungai Bengawan Solo lebar (...).

(3a) Orang tua Halimah (...) kaya (...).

(4a) Anjing putih itu (...) (...) galak.

Berdasarkan ketiga ciri tersebut akhirnya dapat ditemukan macam wujud unsur tambahan, misalnya: amat, agak, benar, benar-benar, belum, cukup, hanya, 
kian, kurang, juga, lebih, makin, nian, paling, saja, sangat, sekali, sedikit, sungguh, tidak.

\section{Distribusi/Ketentuan Letak Unsur Tambahan}

Berdasarkan temuan macam wujud unsur tambahan di atas, akhirnya dapat ditemukan tiga macam distribusi/ketentuan letak unsur tambahan, yaitu: a. berposisi di depan unsur inti, b. berposisi di belakang unsur inti, dan c. berposisi dapat di depan atau di belakang unsur inti. Sajian di di bawah ini membuktikan adanya ketiga macam distribusi/ketentuan letak unsur tambahan yang dimaksud.

\section{Berposisi di Depan Unsur Inti}

Berdasarkan hasil kajian, akhirnya dapat ditemukan macam wujud unsur tambahan yang berposisi di depan dalam frase adjektiva, seperti: amat, agak, belum, benar-benar,cukup, hanya, makin, memang, paling, sangat, sungguh, kurang, kian, lebih, tidak.

Bukti bahwa unsur tambahan berposisi di depan dalam frase adjektiva dapat dilihat pada data (5). Kehadiran: agak, memang, paling dalam frase: agak penyabar, memang penyabar, paling penyebar, berfungsi sebagai unsur tambahan, yang secara dominan berdistribusi di depan kata frase adjektiva. Contoh:

(5) Kakak Marsinah $\{($ agak, memang, paling $)\}$ penyabar.

Bukti bahwa kehadiran unsur tambahan agak, memang, paling berdistribusi di depan dalam farse ajektiva, maka data (5) tidak mungkin diubah menjadi (5a). (5a) *Kakak Marsina penyabar $\{($ agak, memang, paling $)\}$

\section{Berposisi di Belakang Unsur Inti}

Berdasarkan hasil kajian yang ada, akhirnya dapat ditemukan unsur tambahan dalam frase adjektiva yang berposisi di belakang unsur inti, yaitu mencakup: amat, benar, sekali, nian, sungguh, sangat, saja, juga.

Bukti bahwa kehadiran unsur tambahan dalam data (6) berposisi di belakang unsur inti, maka hasil perubahan (6a) tidak mungkin ada/terjadi.

(6) Putri pak Bakri cantik \{(benar, nian, sekali)\}

(6a) *Putri pak Bakri \{( benar, nian, sekali)\} cantik. 
Kehadiran unsur tambahan benar memang tidak mungkin berposisi di belakang unsur inti/pusat. Tetapi setalah mengalami perubahan bentuk benarbenar ternyata dapat ditemukan sebagaimana data (7) dengan sifat yang sama sebagai unsur tambahan, yaitu dapat dilesapkan.

(7) Putri pak Bakri benar-benar cantik.

Data (7) dapat diubah menjadi (7a), tetapi diragukan atau bahkan tidak mungkin berbentuk (7b).

(7a) Putri pak Bakri (...) cantik.

(7b) ?/*Putri pak Bakri cantik benar-benar.

Berposisi Dapat di Depan atau di Belakang Unsur Inti

Unsur tambahan yang berposisi dapat di depan atau di belakang unsur inti merupakan bukti bahwa adanya wujud unsur tambahan yang (relatif) dapat berpindah posisi, yaitu dapat di depan unsur inti/pusat, dan dapat pula di belakang unsur inti/pusat. Perubahan letak posisi yang ada ternyata (relatif) tidak mengganggu makna kalimat yang bersangkutan.

Macam wujud unsur tambahan yang berposisi dapat di depan atau di belakang unti inti/pusat frase adjektiva mencakup: amat, sangat, sungguh. Contoh:

(8) Wajah orang asing itu $\{($ amat, sangat, sungguh $)\}$ cantik.

Data (8) dapat diubah menjadi (8a) dengan relatif tidak mengubah makna dasar kalimat.

(8a) Wajah orang asing itu cantik $\{($ amat, sangat, sungguh $)\}$.

\section{Kemampuan Daya Gabung Antarunsur Tambahan}

Berdasarkan data yang ada, fakta kemampuan daya gabung antarunsur tambahan dalam frase adjektiva banyak dijumpai dalam ragam tulis. Hal semacam berlaku wajar, sebab dalam ragam tulis relatif berlaku ada upaya "penyangatan (penekanan, intensitas)". Fakta kemampuan daya gabung mungkin dalam posisi berjajar atau dalam posisi terpisah. Seperti: agak kurang $+\ldots$, sungguh sangat + ...; sungguh sangat amat $+\ldots$..; kian + ... saja; sungguh amat sangat + ... sekali; sungguh sangat $+\ldots$ nian; benar-benar sangat $+\ldots$ nian; paling sungguh sangat $+\ldots$ sekali; hanya agak sedikit $+\ldots$ saja; kian $($ se $)$ makin $+\ldots$ saja; dan masih banyak lagi. Contoh: 
(9) Cucu nenek itu sungguh sangat cantik.

(10) Paparan semacam hanya agak keliru sedikit saja.

(11) Wajah para artis benar-benar kian menawan saja.

\section{Simpulan}

Berdasarkan hasil sajian analisis unsur tambahan frase adjektiva di atas menunjukkan adanya permasalahan yang kompleks, terlebih khususnya kemampuan daya gabung antarunsur tambahan. Persoalan kemampuan daya gabung yang ada jika diamati lebih lanjut ternyata perlu dilakukan penelitian lebih lanjut, sebab berkemungkinan berkait dengan perilaku sintaksis dan semantik yang lebih kompleks lagi.

Fakta perilaku sintaksis dan semantik yang dimaksud mengisyaratkan pengkajian lebih mendalam lagi. Sebab sangat mungkin persoalan kemampuan daya gabung yang ada berkait dengan pertanyaan baru, misalnya, "Mengapa persoalan daya gabung itu bisa terjadi"; "Apakah faktor kesejajaran makna antarkata yang bergabung berpengaruh atas "penegasan" kalimat"; dan "Apakah pelesapan satu atau dua kata yang mampu daya gabung berpengaruh atas pergerseran makna dasar kalimat?"; dan masih banyak lagi.

\section{Daftar Pustaka}

Kentjono, Djoko (Ed.). 1982. Dasar-dasar Linguistik Umum. Jakarta: Fak.

Sastra UI.

Kridalaksana, Harimurti. 2001. Kamus Linguistik. Jakarta: PT. Gramedia. . 2007. Kelas Kata dalam Bahasa Indonesia. Jakarta: PT Gramedia Pustaka Utama.

Moeliono, Anton M (Ed.). 1988. Tata Bahasa Baku Bahasa Indonesia. Jakarta: Perum Balai Pustaka.

Ramlan, M. 1981. Ilmu Bahasa Indonesia: Sintaksis. Yogyakarta: CV Karyono. 1983. Ilmu Bahasa Indonesia: Morfologi. Yogyakarta: Kanisius. 1985. Tata Bahasa Indonesia Penggolongan Kata. Jogjakarta: Yogyakarta: Andi Offset.

Sudaryanto. 1982. Metode Linguistik: Kedudukannya, Aneka Jemisnya, dan Faktor Penentu Wujudnya. Yogyakarta: Fak Sastra UGM. 
Surono. 2014. Analisis Frasa-Kalimat Bahasa Indonesia. Semarang: Gigih Pustaka Mandiri.

Verhaar, J.W.M . 1977. Pengantar Linguistik. Yogyakarta: Gadjah Mada University Press. 